\title{
THEORETICAL AND EXPERIMENTAL ANALYSIS OF A VAPOR- COMPRESSION REFRIGERATION CYCLE WITH A HEAT EXCHANGER BETWEEN THE SUCTION AND LIQUID LINES
}

\author{
L. S. Santana ${ }^{a}$, \\ J. Castrob, \\ and L. M. Pereira ${ }^{\mathrm{b}}$ \\ ${ }^{a}$ Universidade Federal de Pernambuco \\ Departamento de Engenharia Mecânica \\ Programa de Pós-Graduação em Engenharia \\ Mecânica - PPGEM/UFPE \\ Av. Prof. Moraes Rêgo, 1235 \\ 50670-901, Recife, PE, Brasil \\ leonardosantana800@gmail.com

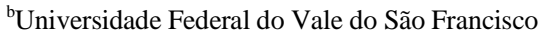 \\ Colegiado de Engenharia Mecânica \\ Av. Antônio Carlos Magalhães, 510 \\ 48902-300, Juazeiro, BA, Brasi \\ castro.silva@univasf.edu.br \\ luiz.mariano@univasf.edu.br \\ ABSTRACT \\ Vapor-compression refrigeration systems require a significant amount of \\ electrical energy. Therefore, there is a need for finding efficient ways of \\ operating this equipment, reducing their energy consumption. The use of \\ heat exchangers between the suction line and the liquid line can produce a \\ better performance of the thermodynamic cycle, as well as reduce it. The \\ present work aims at an experimental analysis of the suction/liquid heat \\ exchanger present in a freezer running with refrigerant fluid R-134a. Three \\ different scenarios were used in order to evaluate the thermal performance \\ of the refrigeration cycle. The first scenario was the conventional freezer set \\ up to collect the required data for further comparison. Moreover, the second \\ and third scenarios were introduced with a $20 \mathrm{~cm}$ and $40 \mathrm{~cm}$ suction/liquid \\ heat exchanger, respectively, into the system. From the experiments, it was \\ observed that the heat exchange does not significantly affect the coefficient \\ of performance (COP) of the freezer. It was concluded from this work that \\ the best scenario analyzed was the $20 \mathrm{~cm}$ suction/liquid heat exchanger \\ where most of the thermodynamic properties were improved, one of them \\ being the isentropic efficiency. \\ Received: January 30, 2019 \\ Revised: February 28, 2019 \\ Accepted: March 29, 2019 \\ Keywords: freezer; R-134a; heat exchanger; COP
}

\section{NOMENCLATURE}

SLHX Suction line heat exchanger

LSHX Liquid Suction Heat Exchanger

$\mathrm{T}_{1} \quad$ Temperature after the evaporator, ${ }^{\circ} \mathrm{C}$

$\mathrm{T}_{2} \quad$ Compressor suction temperature, ${ }^{\circ} \mathrm{C}$

$\mathrm{T}_{4} \quad$ Temperature after the condenser, ${ }^{\circ} \mathrm{C}$

$\mathrm{T}_{5} \quad$ Temperature before the Expansion device, ${ }^{\circ} \mathrm{C}$

$\mathrm{P}_{\mathrm{b}} \quad$ Manometric pressure in the evaporator, $\mathrm{kPa}$

$\mathrm{P}_{\mathrm{a}} \quad$ Manometric pressure in the condenser, $\mathrm{kPa}$

Over Overheating, $\mathrm{K}$

Sub Subcooling, $\mathrm{K}$

$\mathrm{h}_{1} \quad$ Enthalpy of the evaporator outlet, $\mathrm{kJ} / \mathrm{kg}$

$\mathrm{h}_{2} \quad$ Enthalpy at the compressor inlet, $\mathrm{kJ} / \mathrm{k}$

$\mathrm{h}_{3} \quad$ Enthalpy of the compressor outlet, $\mathrm{kJ} / \mathrm{kg}$

$\mathrm{h}_{6} \quad$ Enthalpy at the evaporator inlet, $\mathrm{kJ} / \mathrm{kg}$

$\dot{m} \quad$ Mass flow, $\mathrm{kg} / \mathrm{s}$

$\dot{Q} \quad$ Cooling Capacity, kW

$\dot{W} \quad$ Compression power, $\mathrm{kW}$

$\dot{W}_{s} \quad$ Adiabatic compression power, $\mathrm{kW}$

COP Performance Coefficient

$\eta_{c} \quad$ Isentropic efficiency

$\varepsilon \quad$ Effectiveness of heat transfer

\section{INTRODUCTION}

The steam compression refrigeration cycle is used today in a multifunctional way, being found from a small refrigerator to a large air conditioning installation (Yadav et al., 2015). In 2004, Gonçalves estimated that there were more than 45 million refrigerators in operation in Brazil, of which only a small fraction does not use the principle of mechanical steam compression (Schurt, 2009 citing Gonçalves, 2004), bringing a great demand of electrical energy for this equipment.

The worldwide overall high demand for energy makes the terms energy efficiency or optimization of energy usage a lot more importance. Various present cases studying energy efficiency are related to the science of refrigeration. Therefore, becomes necessary to use and develop equipment with a better performance in order to obtain, not only results in terms of energy savings, but also environmental.

According to Klein et al. (2000), one way to increase the cooling capacity of such equipment is by further cooling the condensed coolant on the highpressure side, which will also cause a decrease in the cooling time of the equipment. One of the methods of 
subcooling the refrigerant in the liquid state is a heat exchange between the liquid at the condenser outlet and the suction steam that returns to the compressor (Dossat, 2004). To achieve this goal, heat exchangers will be installed between these lines, also known as LSHX or SLHX, (Waykole and Dange, 2014).

The heat exchange between the suction and liquid lines can increase the cooling effect, since the amount of steam at the evaporator inlet will be reduced. On the other hand, Mastrullo et al. (2007) made it clear that this change will cause an increase in the temperature of the steam at the inlet of the compressor which will be matched by a larger compression work.

The use of SLHX has been studied by other authors. Domanski et al. (1994) propose a mathematical model to describe the performance of a steam compression refrigeration cycle with a heat exchanger between the suction line and the liquid line, a study complemented by Domanski (1995). Following a similar idea, Negrão and Melo (1999) proposes a model to measure the effectiveness of a heat exchanger formed between the liquid line and the capillary tube. Obtaining similar results to the authors cited at the beginning of this paragraph, Klein et al. (2000) analyzed the impact on the performance and on the pressure drop of a refrigeration system using SLHX. Neto et al. (2006) performed computational simulations for a refrigeration system with a single stage of compression with the SLHX, through the "Coll Pack" software using varied fluids. Mastrullo et al. (2007) presented an operational method to predict the behavior of the system that introduces the SLHX, alternating operation conditions and coolant fluids. Tebchini (2011), Waykole and Dange (2014), and Yadav et al. (2015) conducted experimental investigations using the SLHX in an air conditioner, a water cooler and a household refrigerator respectively.

This work proposes the use of heat regeneration techniques in order to obtain a better performance of a refrigeration equipment by steam compression, conducting experiments under three different scenarios, as well using heat exchangers between the suction line and the liquid line of the equipment.

\section{EXPERIMENTS}

The experimental activities were carried out with a single-stage steam compression refrigeration cycle, contained in a freezer, horizontal type with two doors, Consul manufacture, with a capacity of 404L. Further technical data are given in Tab. 1.

Table 1. Freezer technical data.

\begin{tabular}{|c|c|}
\hline Model & CHB42CBBNA \\
\hline Series & JH3433665 \\
\hline Fluid & R-134a (110g) \\
\hline Voltage & $220 \mathrm{~V} \sim$ \\
\hline Frequency & $60 \mathrm{~Hz}$ \\
\hline Current & $1.3 \mathrm{~A}$ \\
\hline
\end{tabular}

\begin{tabular}{|l|l|}
\hline Power & $0.120 \mathrm{~kW}$ \\
\hline
\end{tabular}

The heat exchange in the internal environment of the equipment is by natural convection and in the condenser by forced convection by a small axial motor fan of direct drive. The compressor is of the alternative type, manufactured by Embraco, model EGAS 80HLR, with use for R-134a fluid, power supply 220-240V and frequency $50-60 \mathrm{~Hz}$; The pressure reduction is done by a capillary tube type expansion device.

The studies were performed in the Refrigeration and Thermofluids' Laboratory, of the Mechanical Engineering Collegiate of the Universidade Federal do Vale do Sao Francisco. The experiments were concentrated under the following scenarios:

- Scenario I: Conventional freezer method, with no heat exchange between the liquid and suction line.

- $\quad$ Scenario II: Method with the installation of a 20 $\mathrm{cm}$ heat exchanger to the freezer, forcing a heat exchange between the liquid and suction lines.

- Scenario III: Method with the installation of a $40 \mathrm{~cm}$ heat exchanger to the freezer, forcing a heat exchange between the liquid and suction lines.

Seven trials were performed, for each scenario, in order to ensure accuracy and consistence. Moreover, a better comparison on the results with detailed data to avoid possible errors caused by the environmental conditions and the experimental procedure. The tests were done on different days, always at the same time (10:30 a.m.) with data extraction (pressures, temperatures and electric power) for every minute. After its completion, the freezer had its doors open in order to equate the internal temperature of the equipment with the room temperature for the next day. The end of the test was determined by reaching the freezer internal temperature to $-18^{\circ} \mathrm{C}$.

The heat exchanger was made of $1 / 4$ "and 1 1/8" gauge hard tubing. The insulator used to insulate the exchanger had wall thickness equal to $10 \mathrm{~mm}$ and made of polyethylene. Two heat exchangers with lengths of $20 \mathrm{~cm}$ (Fig. 2) and $40 \mathrm{~cm}$ (Fig. 1) were made, with similar characteristics, varying only the length of heat exchange.

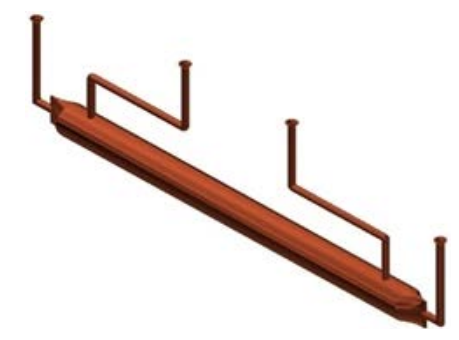

Figure 1. Isometric Perspective of the SLHX $40 \mathrm{~cm}$ (Inventor). 


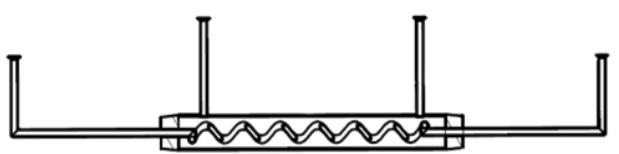

Figure 2. Internal View of the SLHX $20 \mathrm{~cm}$ (Inventor).

The points where the temperature and pressure data were obtained are shown in Fig. 3.

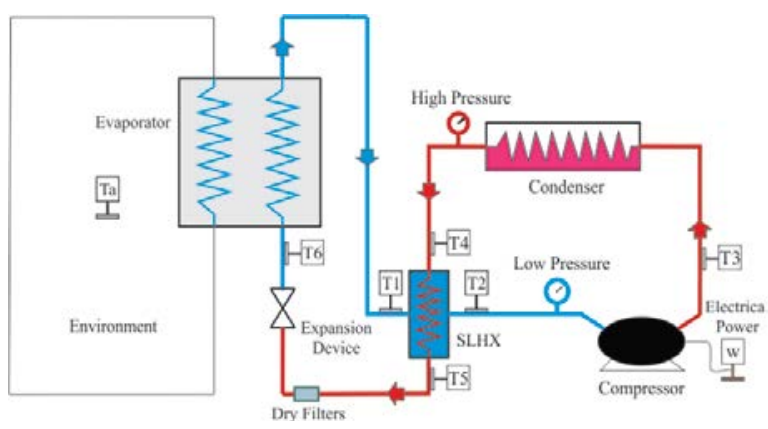

Figure 3. Data collection points in the experiment.

For the temperature data it was assumed that the values concerning the outer surface of the tube is approximately the same as the refrigerant fluid.

The power data was obtained through the serial power meter to the freezer's power cable, assuming that the electrical power of this equipment is approximately the same as the compression power.

\section{COMPUTATIONAL METHOD}

In order to analyze the obtained data, codes were created in the Engineering Equation Solver (EES) software, which contains a built-in library with several mathematical functions and thermophysical properties for hundreds of substances extremely useful for this work.

From a database provided by the manufacturer of the freezer compressor, was found, through the software, a linear regression describing the mass flow rate of the coolant according to the evaporation and condensation temperatures of the refrigerant.

With the pressure and temperature data at the points shown in Fig. 3 and the code developed, it was possible to find the data of superheating and subcooling. Furthermore, it was possible to find several thermodynamic parameters, allowing the evaluation and quantitative comparison of the refrigeration equipment efficiency with and without the presence of SLHX.

\section{Governing Equations}

The energy balance for the refrigeration cycle is based on the application of the first law of thermodynamics for each process, allowing a quantitative analysis of the thermodynamic parameters in the equipment components.

Applying the energy balance in a certain control volume in a steady state, neglecting the variations of kinetic and potential energy, it was possible to find the cooling capacity and the adiabatic compression power.

The cooling capacity is the amount of heat per unit of time, which is withdrawn from the environment to be cooled through the evaporator (Moram and Shapiro, 2002), calculated by Eq. 1.

$$
\dot{Q}=\dot{m}\left(h_{1}-h_{6}\right)
$$

The adiabatic compression power is the amount of energy per unit of time, that must be provided to the coolant, when it leaves the evaporator and is compressed by the compressor to the condenser pressure (Moram and Shapiro, 2002), expressed as:

$$
\dot{W}_{s}=\dot{m}\left(h_{3}-h_{2}\right)
$$

In the actual compression process there is heat transfer, the compressor heats up and loses heat to the environment. Due to the difficult obtaining of this heat portion, in a real experimental research, the compressive power must be obtained by means of the measurement of the electric power of the compressor (Tebchirani, 2011).

With the data of the refrigeration capacity and the compression power, the COP was found, an important parameter to analyze the efficiency of a refrigeration system (Panesi, 2015):

$$
C O P=\frac{\dot{Q}}{\dot{W}}
$$

Another important parameter in the evaluation of the refrigeration equipment behavior is the isentropic efficiency, defined by Çengel and Boles (2013), as a measure, whose function is to evaluate the deviation of real processes in relation to the corresponding idealized processes, in a compressor, it is given by:

$$
\eta_{c}=\frac{\text { theoretical power }}{\text { actual power }}=\frac{\dot{W}_{t}}{\dot{W}_{r}}
$$

\section{Determination of the effectiveness of heat exchangers between the suction line and the liquid line}

The capacity of the heat exchanger between the suction line and the liquid line to transfer energy at steady state depends on its dimensions and the configuration of the heat transfer device (Tebchirani, 2011). Kays and London suggested, in 1955, the effectiveness method - NTU as a way of simplifying the analysis of heat exchangers. This method is based on a dimensionless parameter of performance analysis called heat transfer effectiveness (

ع) given by a ratio between the real heat transfer rate and the 
maximum possible heat transfer rate (Çengel and Ghajar, 2012).

The specific heat of the steam is smaller than the liquid one, so the temperature increase of the steam, that flows through the suction line, will always be greater than the reduction of the liquid temperature (Dossat, 2004). Thus, the effectiveness of heat transfer in a heat exchanger between the suction line and the liquid line is determined by:

$$
\varepsilon=\frac{\left(T_{\text {vapor,outlet }}-T_{\text {vapor, } \text { inlet }}\right)}{\left(T_{\text {liquid, } \text { inlet }}-T_{\text {vapor, }, \text { inlet }}\right)}=\frac{\left(T_{2}-T_{1}\right)}{\left(T_{4}-T_{1}\right)}
$$

\section{RESULTS AND DISCUSSION}

The results were expressed in a comparative way between the three presented scenarios in order to develop a thorough analysis of variations found in each of the experiments. Therefore, the main purpose of the investigations was to determinate advantages and disadvantages of SLHX on an operating freezer. The principal values of temperature and pressure obtained in the experiments are shown in Tab. 2.

Table 2. Average values of temperature $\left({ }^{\circ} \mathrm{C}\right)$ and pressure $(\mathrm{kPa})$ obtained in the experiment.

\begin{tabular}{|c|c|c|c|}
\hline \multirow{2}{*}{$\begin{array}{c}\text { Obtained } \\
\text { data }\end{array}$} & \multicolumn{3}{|c|}{ Scenario } \\
\cline { 2 - 4 } & I & II & III \\
\hline $\mathrm{T}_{1}$ & - & 32.28 & 32.81 \\
\hline $\mathrm{T}_{2}$ & 30.52 & 35.49 & 36.59 \\
\hline $\mathrm{T}_{4}$ & - & 41.13 & 41.04 \\
\hline $\mathrm{T}_{5}$ & 37.89 & 39.58 & 40.65 \\
\hline $\mathrm{P}_{\mathrm{b}}$ & -6.86 & 6.02 & -1.43 \\
\hline $\mathrm{P}_{\mathrm{a}}$ & 1030.29 & 1153.71 & 1106.29 \\
\hline
\end{tabular}

From the measurements obtained in Tab. 2, the performance parameters of the equipment were calculated through the EES software for the three proposed scenarios. The mean values obtained are shown in Tab. 3.

Table 3. Average of the performance parameters obtained.

\begin{tabular}{|c|c|c|c|}
\hline \multirow{2}{*}{ Parameters } & \multicolumn{3}{|c|}{ Scenario } \\
\cline { 2 - 4 } & I & II & III \\
\hline COP & 1.40 & 1.45 & 1.39 \\
\hline Cooling Capacity & 0.1917 & 0.2159 & 0.1978 \\
\hline Compression Power & 0.1359 & 0.1482 & 0.1409 \\
\hline Mass flow & 0.0011 & 0.0012 & 0.0011 \\
\hline Over. at the point T1 & - & 57.23 & 59.35 \\
\hline Over. at the point T2 & 58.24 & 60.44 & 63.12 \\
\hline Sub. at the point T4 & - & 6.85 & 5.44 \\
\hline Sub. at the point T5 & 6.05 & 8.39 & 5.83 \\
\hline
\end{tabular}

From the interpretation of Tab. 3, we have a detailed analysis of the influence of the introduction of SLHX on some of the performance parameters of the equipment.

\section{Effect on Subcooling - Liquid Line}

There is a $38.68 \%$ increase in subcooling after using a $20 \mathrm{~cm}$ heat exchanger and a reduction of $3.64 \%$ in the $40 \mathrm{~cm}$ exchanger when compared to the scenario without the SLHX. Comparing the values obtained in the previous (T4) and posterior (T5) points to the SLHX, there was an increase in the subcooling caused by the $20 \mathrm{~cm}$ and $40 \mathrm{~cm}$ heat exchangers, in the values of $1.54 \mathrm{~K}$ and $0.39 \mathrm{~K}$, respectively.

\section{Effect on Overheating - Suction Line}

There is a gradual increase in overheating with the heat exchange between the suction line and the liquid line. The introduction of the $20 \mathrm{~cm}$ SLHX presented a 3.78\% increase in overheating over conventional freezer operation, while the $40 \mathrm{~cm}$ SLHX provided an increase of $8.38 \%$ at the same point. When compared to the points before and after the SLHX, it was verified that the increase in the superheat caused by the heat exchangers of 20 and 40 $\mathrm{cm}$ are very close, $3.21 \mathrm{~K}$ and $3.77 \mathrm{~K}$, respectively.

\section{Effect on Cooling Capacity}

With the introduction of the heat exchanger the refrigeration cycle had an increase in its cooling capacity, caused by the increase in the subcooling area at the inlet of the expansion device. In percentage terms, the increase of the refrigeration capacity caused by the heat exchange between the suction line and the liquid line in the SLHX of $20 \mathrm{~cm}$ was $12.65 \%$, whereas in the SLHX of $40 \mathrm{~cm}$ the increase was only $3.20 \%$. The Fig. 4 presents values of the relation between refrigeration capacity in the refrigeration cycle with and without the presence of SLHX for each test.

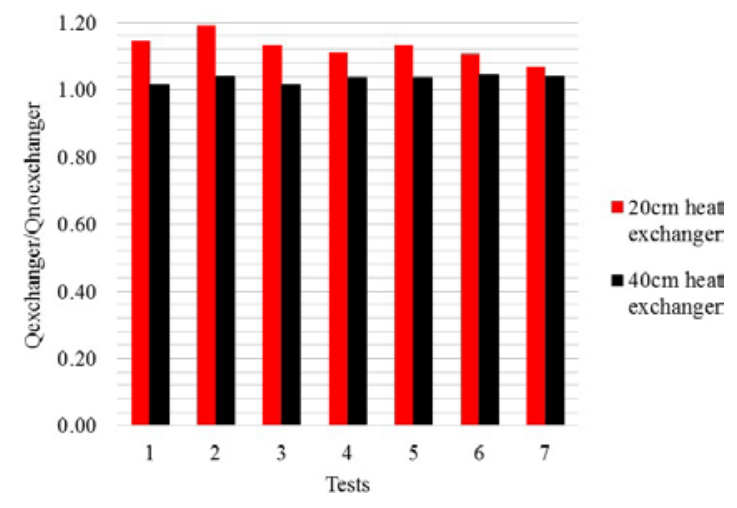

Figure 4. Relation between the refrigerating capacities.

\section{Effect on the compression power}

It is observed an increase of the electric power caused by an increase in the compression power for the scenarios with the presence of the heat exchanger in the cycle. The increase in the superheating, as affirmed by Dossat (2004), influenced in an increase 
of the compression power due to the increase of the specific volume of the coolant fluid in the entrance of the compressor.

Although the temperature increase in the suction of the refrigeration cycle with the SLHX of $40 \mathrm{~cm}$ was higher, it presented an increase of the electric power consumption when compared to the conventional operation of the freezer, in the percentage value of $3.74 \%$, lower than the increase caused by the $20 \mathrm{~cm}$ heat exchanger, which influenced a power increase of $9.05 \%$. The Fig. 5 shows values of the ratio between the compression power in the refrigeration cycle with and without the presence of the heat exchanger between the suction line and the liquid line for each test.

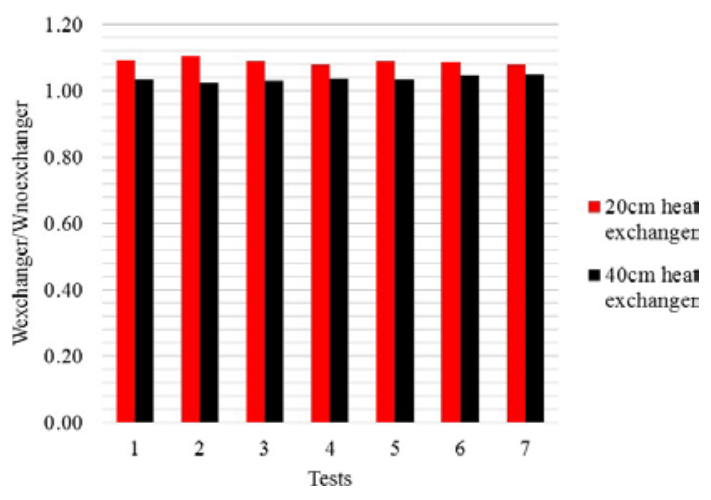

Figure 5. Ratio between the compression powers.

\section{Effect on Performance Coefficient}

It is noticeable that the increase in the cooling capacity is compensated by the increase of the compression power, making the performance variation performance coefficient small. However, the proportion of increase in compression, caused by the presence of SLHX of $20 \mathrm{~cm}$ between the suction and liquid lines in 6 out of 7 experiments, is smaller than the proportion of the increase in the cooling capacity, thus making the average coefficient 3.57\% higher than the conventional freezer operating mode. Using SLHX of $40 \mathrm{~cm}$ presented a reduction of $0.71 \%$. For a better visualization, Fig. 6 shows the relation between the values found for the coefficient of performance of the refrigeration cycle with and without the presence of SLHX for each test.

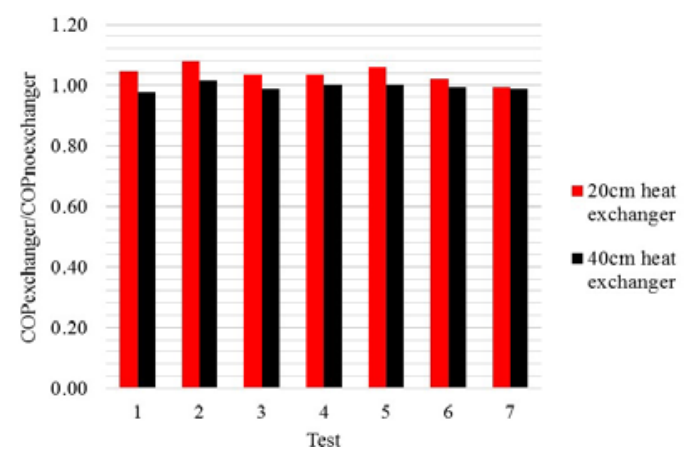

Figure 6. Ratio between the COP values.
The increase in the cooling capacity caused a reduction in the cooling time to reach the temperature of $-18^{\circ} \mathrm{C}$. The Fig. 7 presents the behavior of the temperature as a function of time, for three tests, one for each type of scenario, with the same initial internal temperature, equal to $25.4^{\circ} \mathrm{C}$.

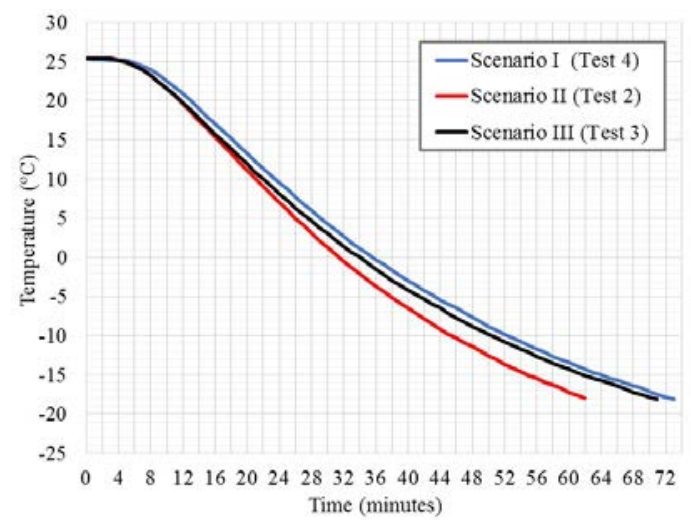

Figure 7. Behavior of internal temperature $\left({ }^{\circ} \mathrm{C}\right)$ as a function of time (minutes).

In addition to the performance parameters presented in Tab. 3, another parameter was found and had relevance to the study.

\section{Effect on isentropic efficiency}

For the analysis of the isentropic efficiency, the power values were first found, considering the process of isentropic compression, that is, adiabatic and reversible. The average of these results are presented in Tab. 4.

Table 4. Average values of theoretical power (kW).

\begin{tabular}{|c|c|c|c|}
\hline Scenario & I & II & III \\
\hline Average & 0.0715 & 0.0815 & 0.0767 \\
\hline
\end{tabular}

With the theoretical and actual power data, it was possible to find isentropic efficiency (Tab. 5).

Table 5. Average values for isentropic efficiency of the compressor (\%).

\begin{tabular}{|c|c|c|c|}
\hline Scenario & I & II & III \\
\hline Average & 52.39 & 55.00 & 54.12 \\
\hline
\end{tabular}

Analyzing the averages obtained for the isentropic efficiency, there is a small increase in relation to the conventional mode of operation of the freezer, in the order of $4.98 \%$ for scenario II and $3.30 \%$ for scenario III, in other words, for both cases, the introduction of the heat exchanger between the suction and liquid lines allows the reduction of the losses resulting from the deviation of an actual compression cycle from an ideal cycle.

Effectiveness of the heat exchanger between the suction line and the liquid line 
Table 6 presents the average value of the effectiveness in each of the two heat exchangers analyzed, calculated from Eq. (5). It can be seen that the increase in the length of the exchanger caused an increase of $19.44 \%$ on its performance.

Table 6. Average values found for effectiveness.

\begin{tabular}{|c|c|c|}
\hline Exchanger & $\mathbf{2 0} \mathbf{~ c m}$ & $\mathbf{4 0} \mathbf{~ c m}$ \\
\hline Average & 0.36 & 0.43 \\
\hline
\end{tabular}

Figure 8 shows the behavior of the ratio between the refrigeration capacities, shown in Fig. 4, as a function of the efficiency of the exchanger, for each test.

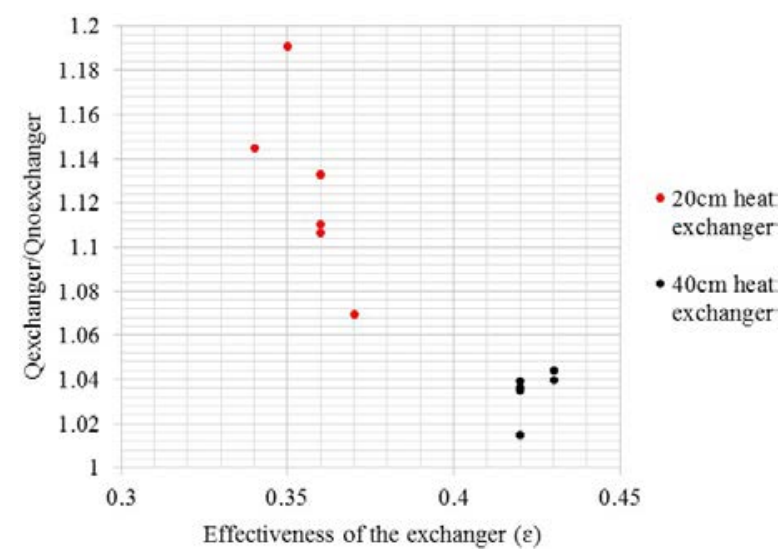

Figure 8. Behavior of the relationship between refrigeration capacities as a function of heat exchanger effectiveness.

An increase in freezer refrigeration potential is observed when the effectiveness of the heat exchanger is close to $35 \%$. Values above $35 \%$ begin to show a reduction in the proportion of the amount of heat withdrawn from the internal environment. In spite of this significant increase, which mainly involved reducing the time spent for internal cooling, the increase in useful superheat at the compressor inlet caused by the heat exchange with the liquid line also caused an increase in the specific volume of the fluid, consequently implying in a compression power increase.

Figure 9 demonstrates that in almost all cases the $20 \mathrm{~cm}$ heat exchanger provides an increase in the performance coefficient, which is greater when the efficiency of the exchanger is equal to $35 \%$.

The effectiveness analysis also shows that although the $40 \mathrm{~cm}$ exchanger is more effective and has a greater capacity to transmit energy, this increase corresponds in a contrary way to the performance of the freezer. Only the experiment 2 with the $40 \mathrm{~cm}$ heat exchanger showed an efficiency above $36 \%$ and a COP with a small increase over the conventional mode of equipment operation. For all other experiments that showed an effectiveness greater than this percentage, there was a reduction in the performance coefficient.

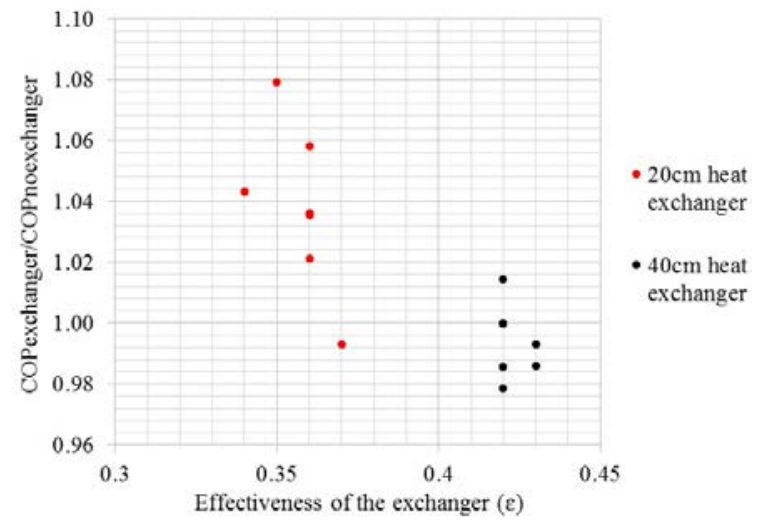

Figure 9. Actual COP as a function of the heat exchanger effectiveness.

\section{CONCLUSIONS}

The present work evaluated the thermodynamic behavior of a steam compression refrigeration cycle using R-134a as refrigerant, comparing a conventional equipment cycle and cycles using heat exchangers between the suction line and the liquid line. The tested exchangers were $20 \mathrm{~cm}$ and $40 \mathrm{~cm}$ long.

After all the seven tests being carried out, for each of the stipulated scenarios, it was possible to compare the cooling rate and the thermodynamic efficiency of the cooling cycles experienced. Moreover, the influence of the compressor isentropic efficiency, as well the relationship between the heat exchanger and the equipment performance.

The cycles with the presence of SLHX, regardless of length, presented a considerable increase in the isentropic efficiency of the compressor, demonstrating then, a much more efficient cycle. The introduction of the heat exchangers between the suction line and the liquid line of $20 \mathrm{~cm}$ and $40 \mathrm{~cm}$ presented an increase of $3.78 \%$ and $8.38 \%$, respectively, in the total overheating of the cycle. For the $20 \mathrm{~cm}$ component, this increase in overheating was useful, since the heat exchange provoked a $38.68 \%$ increase in the sub cooling of the cycle. This increase in sub cooling also provided an increase in the cooling capacity of the equipment to approximately 216 watts.

The average effectiveness of the heat exchanger was increased by $19.44 \%$ when the length of the heat exchanger was increased from $20 \mathrm{~cm}$ to $40 \mathrm{~cm}$. In addition, this increase provided a reduction in thermodynamic efficiency of the freezer. It was also observed that COP was higher when the effectiveness was equal to 0.35 .

Therefore, it is possible to concluded that the use of SLHX with a length of $20 \mathrm{~cm}$ was the best option among the studied ones, due to the increase of the refrigerating capacity in $12.65 \%$. Consequently, a 
small but significant variation of the performance coefficient was obtained, as well as an average reduction of 8 minutes in the operating time spent to reach the temperature of $-18^{\circ} \mathrm{C}$.

\section{REFERENCES}

Boles, M. A., and Çengel, Y. A., 2013, Termodinâmica, 7th, AMGH Editora. (in Portuguese)

Çengel, Y. A., and Ghajar, A. J., 2012, Transferência de Calor e Massa: uma Abordagem Prática, 4th Edition, McGraw-Hill Book Company. (in Portuguese)

Domanski, P. A., 1995, Theoretical Evaluation of the Vapor Compression Cycle with a LiquidLine/Suction-Line Heat Exchanger, Economizer, and Ejector, National Institute of Standards and Technology, Gaithersburg, MD, USA.

Domanski, P. A., Didion, D. A., and Doyle, J. P., 1994, Evaluation of Suction-Line/Liquid-Line Heat Exchange in the Refrigeration Cycle, International Journal of Refrigeration, Vol. 17, No. 7, pp. 487-493.

Dossat, R. J., 2004, Princípios de Refrigeração, Editora Hemus. (in Portuguese)

Klein, S. A., Reindl, D. T., and Brownell, K., 2000, Refrigeration System Performance Using Liquid-Suction Heat Exchangers, International Journal of Refrigeration, Vol. 23, No. 8, pp. 588-596.

Mastrullo, R., Mauro, S. T., and Vanoli, G. P, 2007, A Chart for Predicting the Possible Advantage of Adopting a Suction/Liquid Heat Exchanger in Refrigerating System, Applied Thermal Engineering, Vol. 27, No. 14, pp. 2443-2448.

Moran, M. J., and Shapiro, H. M., 2002, Princípios de Termodinâmica para Engenharia, 4th Edition, LTC. (in Portuguese)

Negrão, C. O., and Melo, C., 1999, Modelo Simplificado para Trocador de Calor Tubo CapilarLinha de Sucção, in: Proceedings of the XV COBEM, Águas de Lindóia, SP. (in Portuguese)

Neto, J. H. M., Veloso, A. H. B., and Fernandes, A. F. C., 2006, Simulação Computacional Simplificada de Sistemas de Refrigeração por Compressão a Vapor, in: Simpósio de PósGraduação em Engenharia Mecânica, Uberlândia MG. (in Portuguese)

Panesi, R. , 2015, Termodinâmica para Sistemas de Refrigeração e Ar Condicionado, 1st Edition, Artliber. (in Portuguese)

Schurt, L. C., 2009, Modelagem Matemática e Controle Multivariável de Sistemas de Refrigeração por Compressão Mecânica de Vapor, Master Thesis, Universidade Federal de Santa Catarina, Florianópolis, SC. (in Portuguese)

Tebchirani, T. L., 2011, Análise Termodinâmica Experimental de um Sistema de Ar Condicionado Split Utilizando um Trocador de Calor Linha de Sucção/Linha de Líquido, Master Thesis, Universidade Federal do Paraná, Curitiba, PR. (in Portuguese)
Waykole, C. P., and Dange, H. M., 2014, Performance Evaluation of Water Cooler with Modification of Liquid Suction Heat Exchanger, International Journal of Current Engineering and Technology, Special Issue -3, pp. 226-229.

Yadav, G. M. P., Prasad, P. R., and Veeresh, G., 2015, Experimental Analysis of Vapour Compression Refrigeration System with Liquid Line Suction Line Heat Exchanger by Using R134A and R404A, International Journal of Scientific Research and Management Studies (IJSRMS), Vol. 1, No. 12. 